\title{
ARTIGOS
}

\section{ESTUDO IMUNOBIOLÓGICO DE ESTOQUES DE TRYPANOSOMA CRUZI ISOLADOS DE PACIENTES NA FASE AGUDA DA DOENÇA DE CHAGAS}

\section{Principais parâmetros da infeção produzida no camundongo}

\author{
T.L. Kipnis, P.M. Minóprio, A.O. Luquetti, A. Rassi e W. Dias da Silva
}

Estoques de tripanossomas isolados de pacientes na fase aguda da doenca de Chagas foram injetados em grupos de camundongos albinos não isogênicos nas doses de $10^{3}, 10^{4}$ e $10^{5}$ parasitas/camundongos. $O$ curso da infecçäo foi seguido por três meses. A patrasitemia foi em geral baixa, com picos recorrentes, na maioria das vezes os animais evoluiam para cronicidade. Somente um estoque induziu alto indice de mortalidade. Os parasitas $e$ as lesōes apesar de detectadas no pico da parasitemia $e$ restritos ao coraç̄óo estavam ausentes aos três meses. Nesta época os perfis de Igs apresentaram diferenças marcantes. Grupos de animais que foram inoculados com estes estoques foram desafiados com doses letais da cepa Y ou CL. Em alguns casos obteve-se uma parasitemia, mas patente.

Palavras chaves: Trypanosoma cruzi. Doença de Chagas. Estoques. Cepas. Isotipos de IgG.

Os mecanismos acionados pelo sistema imunitário dos hospedeiros vertebrados no decurso da infecção pelo Trypanosoma cruzi vêm sendo intensivamente investigados usando-se como modelo básico, a infecção de animais de laboratório tais como camundongos, rato, coelho e mais raramente primatas com cepas de $T$. cruzi mantidas em laboratório, via de regra, por passagens sucessivas de camundongo a camundongo. Abstraindo-se a questão sobre se os hospedeiros comumente usados seriam os mais adequados para esclarecer os fenômenos imunopatológicos ou imunobiológicos que acontecem na doença humana ou no "equilíbrio de convivência" entre o parasita e seus reservatórios silvestres, pelo menos duas perguntas hão de ser feitas: a) As diferentes cepas de $T$. cruzi extensivamente empregados como agentes ou fontes de agentes imunizantes são potencialmente capazes de acionar os mecanismos imunitários funcionantes nas infecções naturais? b) $\mathrm{O}$ emprego de tais cepas como células-alvo no estudo dos diferentes

Trabalho financiado por FAPESP, CNPq e UNDP/World Bank/WHO. Special Programme for Research and Training in Tropical ! Diseases. Departamento de Imunologia, Instituto de Ciências Biomédicas da Universidade de São Paulo, Departamento de Parasitologia, Instituto de Patologia Tropical da Universidade Federal de Goiás e Departamento de Clínica Médica da Faculdade de Medicina da Universidade Federal de Goiás.

Recebido para publicação em 9/5/1983. mecanismos imunes efetores, tanto humorais como celulares, fornece informações transferiveis para os mecanismos efetores similares, desencadeados pelos tripanossomas presentes nos reservatórios silvestrés e/oú causando doença humana nas zonas endêmicas?

A pertinência de tais questőes reforça-se pelo fato já amplamente documentado, de que, apesar da grande semelhança morfológica e antigênica existente entre as cepas conhecidas de $T$. cruzi, estudos experimentais têm revelado acentuadas dife. renças entre cepas com respeito, principalmente, à capacidade de sobrevivência e/ou multiplicação ou diferenciação do parasita dentro de certas célu$\operatorname{las}^{29}$ e sua susceptibilidade à ação de um particular mécanismo imune efetor ${ }^{1} 1012$.

Com o objetivo de tentar esclarecer essas questð̃es decidimos analisar alguns parâmetros imunobiopatológicos de estoques de $T$. cruzi colhidos de pacientes não tratados, na fase aguda da doença de Chagas e provenientes da mesma área endêmica. No presente trabalho, são apresentados os resultados relativos à infectividade, virulência, distribuição tecidual dos parasitos e lesōes, e estimulação da produção policlonal de IgG durante a infecção experimental produzida em camundongos não isogênicos com 10 diferentes estoques recentemente isolados de $T$. cruzi. 


\section{MATERIAL E MÉTODOS}

Estoques de $T$. cruzi - No presente trabalho foram usados 10 estoques de $T$. cruzi obtidos de pacientes não tratados e na fase aguda da doença de Chagas. Logo em seguida ao fechamento do diagnóstico por meio de exames clínico e laborato- rial, os pacientes eram submetidos ao xenodiagnóstico com Triatoma infestans. Na Tabela 1 encontram-se os dados referentes aos pacientes dos quais foram isolados os estoques de $T$. cruzi utilizados. As cepas de $T$. cruzi $\mathrm{Y}$ e $\mathrm{CL}$, usadas como parâmetro, são mantidas neste laboratório através de passagens sucessivas de camundongo para camundongo.

Tabela 1 - Dados referentes aos pacientes dos quais foram isolados os estoques de Trypanosoma cruzi

\begin{tabular}{|c|c|c|c|c|c|c|c|c|c|c|c|c|c|c|c|c|c|}
\hline \multirow[b]{2}{*}{ No estoque } & \multicolumn{3}{|c|}{ Identificafăoo } & \multirow[b]{2}{*}{$\begin{array}{l}\text { municlpio } \\
\text { (I) }\end{array}$} & \multirow[b]{2}{*}{ zona } & \multirow[b]{2}{*}{$\begin{array}{l}\text { dias } d x \\
\text { infeç̧ä́ }\end{array}$} & \multirow[b]{2}{*}{$\begin{array}{l}\text { parta de } \\
\text { entrada }\end{array}$} & \multirow[b]{2}{*}{ febre } & \multicolumn{3}{|c|}{ Caracteristicas Clinicas } & \multirow[b]{2}{*}{$\begin{array}{l}\text { edema } \\
\text { sub- } \\
\text { cutâneo. }\end{array}$} & \multirow[b]{2}{*}{$\begin{array}{l}\text { miocar } \\
\text { dite } \\
\text { (2) } \\
\end{array}$} & \multirow[b]{2}{*}{ direto (3) } & \multicolumn{2}{|c|}{ Exames } & \multirow[b]{2}{*}{$F C(4)$} \\
\hline & intciais & sexo & idade & & & & & & $\begin{array}{l}\text { hipertro- } \\
\text { fia lin- } \\
\text { fonodos }\end{array}$ & $\begin{array}{l}\text { hepato. } \\
\text { megalia }\end{array}$ & $\begin{array}{l}\text { espleno- } \\
\text { megalia }\end{array}$ & & & & $\begin{array}{l}\text { sorologia } \\
\text { IgM }\end{array}$ & $\begin{array}{c}- \text { Imunof } \\
l g G\end{array}$ & \\
\hline 1 & ERS & $\mathbf{M}$ & 8 & Montal. & nural & 17 & Romaña & $\operatorname{sim}$ & $\operatorname{sim}$ & กลิo & กão & $\operatorname{sim}$ & não & + & 16 & 64 & \\
\hline 2 & MRSG & $\mathrm{F}$ & 4 & Montal. & urbana & 12 & Ausente & กลั๋ & $\sin$ & não & กล̃o & sim & não & + & 16 & 64 & $\begin{array}{l}2,8 \\
1,8\end{array}$ \\
\hline 3 & MLSG & $\mathbf{F}$ & 12 & Montal. & urbana & 27 & Romaña & $\operatorname{sim}$ & $\operatorname{sim}$ & กม̃̃o & กม̃o & $\operatorname{sim}$ & não & + & 1.024 & 24 & 2,8 \\
\hline 4 & SLJ & $\mathrm{F}$ & 62 & Montal. & rural & 32 & Chagoma & $\operatorname{sim}$ & $\sin$ & não & กลัo & não & กลี้ & + & 128 & 256 & 2,2 \\
\hline 5 & CPO & $\mathrm{F}$ & 53 & Carinh. & rural & 20 & Chagoma & sim & กี艹 & sim & กลั้ & ñ̄o & กล̃o & + & 40 & 80 & $\mathrm{AC}^{5}$ \\
\hline 6 & DPS & $\mathrm{F}$ & 10 & Barr. & nural & 55 & Romaña & sim & sim & sim & sim & não & não & + & 128 & 256 & $\begin{array}{l}\mathrm{AC}- \\
2,7\end{array}$ \\
\hline 7 & AHML & M & 10 & Montal. & nural & 14 & Romaña & $\operatorname{sim}$ & năo & กล̃o & $\operatorname{sim}$ & sim & กล้o & + & 10 & 20 & 2,8 \\
\hline 8 & ICF & $\mathrm{F}$ & 10 & Montal. & rural & 14 & Roman̂a & $\operatorname{sim}$ & $\operatorname{sim}$ & sim & nầ & กลัo & กลัด & + & 5 & 20 & $\begin{array}{l}2,6 \\
2,8\end{array}$ \\
\hline 9 & HVNM & M & 12 & Montal. & rural & 13 & Chagoma & sim & não & naี̃o & กอัด & กิ๊o & nầo & + & + & 80 & $\begin{array}{l}2,8 \\
2,8\end{array}$ \\
\hline 10 & RST & $\mathbf{M}$ & 10 & Coteg. & nural & 20 & Chagoma & sim & sim & sim & sim & sim & nẫo & + & + & + & $\begin{array}{l}2,8 \\
1,8\end{array}$ \\
\hline
\end{tabular}

(1). Refere-se ao município onde foi contraida a doença - Montal.: Montalyânia (MG), Carinh.: Carinhanha (BA),

(2) Miocardite pexquise Barr.: Barreiras (BA), Cotegipe (BA)

(2) Miocardite pesquisada por eletrocardiograma e radiografia de tórax seriados.

(3) Pesquisa a fresco do sengue periféricc entre lâmina e lamínula.

(4)Fixação do complemento pela técnica de Freitas e Almeida (4), realizada pelo Depto de Parasitologia, Microbiologia e Imunologia da Fac. de Medicina de Ribeirão Preto (5) Soro anticomplementar - AC.

Obtenção das formas metacíclicas - Os triatomíneos foram anestesiados com éter, presos sobre pranchas de disseç̧ão, o abdome aberto, o trato digestivo dissecado, o reto retirado e aberto e o seu conteúdo depositado em placas de Petri contendo tampão fosfato-salina, $\mathrm{pH} 7,5, \mu=0.15$ (TFS), e penicilina $(500 \mathrm{U} / \mathrm{ml})^{\prime} \in$ estreptomicina $(500 \mu \mathrm{g} / \mathrm{ml})$. Após passagem em gaze, as formas metacíclicas foram enumeradas e inoruladas pela via intraperitoneal (i.p.) em camundongos $\mathrm{A} / \mathrm{Sn}$ ou $\mathrm{C} 3 \mathrm{H} / \mathrm{He}$ previamente irradiados com 570 rads (fonte de Césio) e a parasitemia avaliada a cada 3 dias.

Obtenção dos tripomastigotas sangüíneos Uma vez obtidas parasitemias patentes, os animais foram sangrados, o sangue misturado com igual volume de TFS contendo $5 \mathrm{U} / \mathrm{ml}$ de heparina, os tripanossomas enumerados e as suspensðes ajustadas para $10^{5}, 10^{4}$ e $10^{3}$ formas tripomastigotas/ ml. Tripomastigotas sangüíneos das cepas Y e CL eram obtidos também de camundongos $\mathrm{A} / \mathrm{Sn}$ ou $\mathrm{C} 3 \mathrm{H} / \mathrm{He}$ previamente irradiados. Para a execução dos experimentos, formaram-se grupos homogêneos de 7 camundongos albinos, não isogênicos e com 5 a 6 semanas de idade pesando $17 \pm 1 \mathrm{~g}$. Para cada estoque ou cepa de tripanossomas foram usados 3 grupos de camundongos machos e 3 grupos de camundongos fêmeas, designados IF e IM, IIF e IIM, IIIF e IIIM. Estes camundongos foram injetados i.p. com $1,0 \mathrm{ml}$ das suspensões $10^{3} / \mathrm{ml}$ (grupos IF e IM), $10^{4} / \mathrm{ml}$ (grupos IIF e IIM) e $10^{5} / \mathrm{ml}$ (grupos IIIF e IIIM). Os experimen- tos de reinfecção destinados a verificar a possível indução de imunização cruzada foram feitos utilizando-se grupos de 6 a 7 camundongos que evoluiram para a cronicidade. Três meses após a primo-infecção, os camundongos eram reinoculados com $10^{5}$ tripomastigotas sangüíneos das cepas $\mathrm{Y} e$ CL também obtidas de camundongos previamente irradiados.

Preparq dos tecidos para exames histopatológfcos - De cada grupo foram retirados 3 camundongos com parasitemia patente, os quais eram saçificados e fragmentos de coração, baço, diafragma, fígado, esôfago, duodeno, colo e ceco, fixados em líquido de Bouin e os cortes obtidos corados pela hematoxilina-eosina. Fragmentos de tais órgãos foram obtidos, também, de camundongos na fase crônica ( 3 meses) da infecção e processados da mesma maneira.

Preparo dos tripanossomas para exames morfológicos - Suspensões ricas em tripanossomas eram depositadas sobre lâminas, os parasitos fixados com metanol e as lâminas coradas pelo método de Giemsa.

Avaliação da parasitemia - Foi usado o método descrito por Brener ${ }^{5}$.

Fracionamento dos soros de camundongo em coluna de proteína

A - Sepharose - Lotes de 6 camundongos eram sangrados aos 3 meses após a infecção e os 
Kipnis TL, Minbprio PM, Luquetti AO, Rassi A, Dias da Silva W. Estudo imunobiolbgico de estoques de Trypanosoma cruzt isolados de pacientes na fase aguda da doença de Chagas. Revista da Sociedade Brasileira de Medicina Tropical 16:175-183, Out-Dez, 1983

soros obtidos passados em filtros de Millipore (Millipore, Co.) com poros de $0,2 \mu \mathrm{m}$. Dois mililitros de soro eram misturados com igual volume de tampão-tris-HC1, $\mathrm{pH} \mathrm{8,6, \mu}=0.15$ e passados na coluna de proteína A-Sepharose previamente equilibrada com este mesmo tampão. Após lavagem da coluna com este tampão até a absorbância do efluente atingir valores próximos de 0,02 os diferentes isótipos de IgG eram eluidos, sucessivamente, com os tampð̃es fosfato-salina, $\mathrm{pH} 7,0$, $\mu=0.15$, citrato-ácido cítrico-salina, $\mathrm{pH5}, 5, \mu=$ 0.15 , fosfato-salina, $\mathrm{pH} 4,3, \mu=0.15$ e glicina$\cdot \mathrm{HC} 1$ salina, $\mathrm{pH}^{\prime} 2,8, \alpha=0.15$. Os efluentes correspondentes a cada eluiçăo eram reunidos, o teor em proteínas determinado pelo método de Lowry e col. ${ }^{10}$ e referido em termos de proteínas totais eluidas por tampão. $\mathrm{Na}$ padronização preliminar da coluna utilizando misturas de soros de camundongos na fase crônica da infecção pelo T. cruzi e soros monoespecíficos anti-isótipos de IgG de camundongos, verificou-se que o tampão pH 5,5 eluiu, predominantemente, IgG1, o tampão
pH 4,3 eluiu IgG2b e o tampão pH 2,5, Ig2a com traços de IgG2b. IgG3 năo foi détectado. Os antissoros monoespecíficos foram gentilmente cedidos pelo Prof. Dr. Ivan Mota - Departamento de Imunologia, ICB, USP e as análises feitas pelo método de dupla-difusão em gel de agarose.

Pesquisa de anticorpos específicos - Foi utilizado o método descrito por Freitas e Almei$\mathrm{da}^{7}$ para a fixação do complemento e o método da imunofluorescência indireta ${ }^{6}$ para $^{\prime}$ dosar os anticorpos específicos.

\section{RESULTADOS}

Características gerais da infecção experimental - Na Tabela 2 e Figura 1 encontram-se os principais dados referentes às infecçðes produzidas em camundongos não isogênicos com $10^{5}$ tripomastigotas pertencentes aos 10 diferentes estoques de T. cruzi recentemente isolados de pacientes na fase aguda da doença de Chagas.

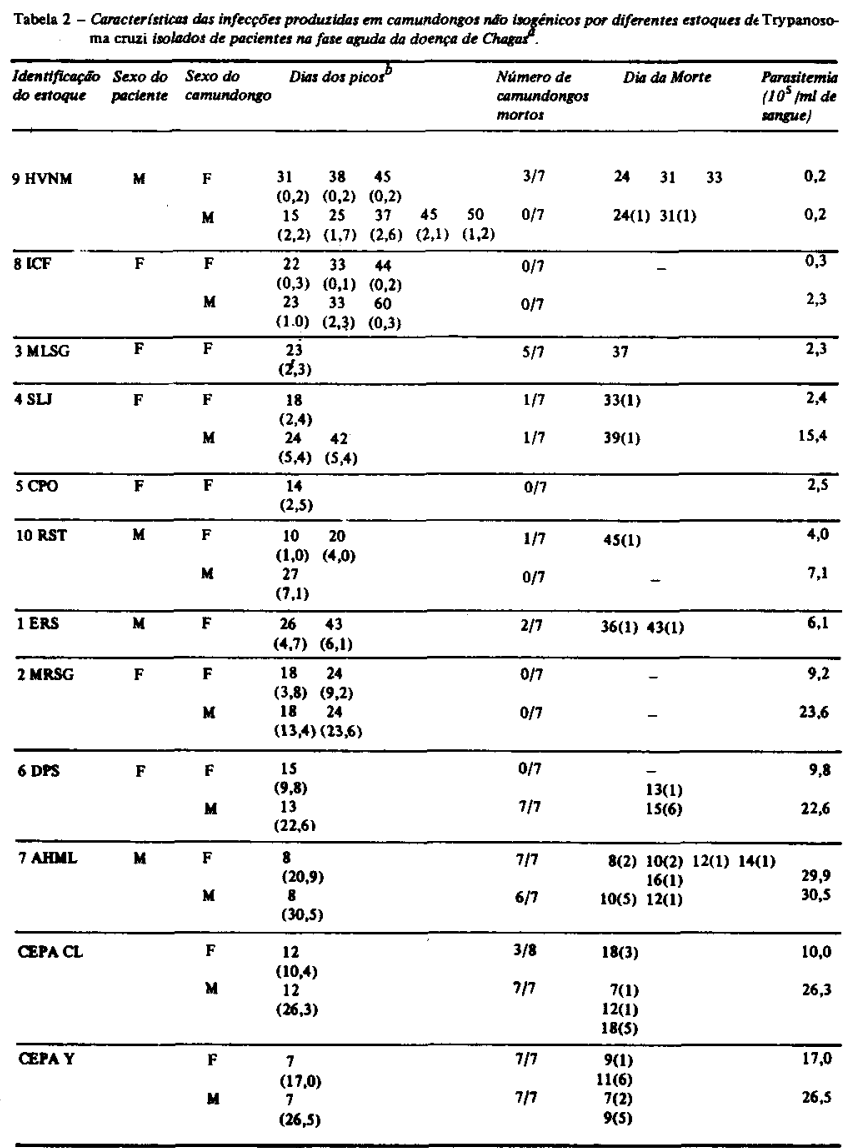

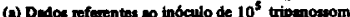



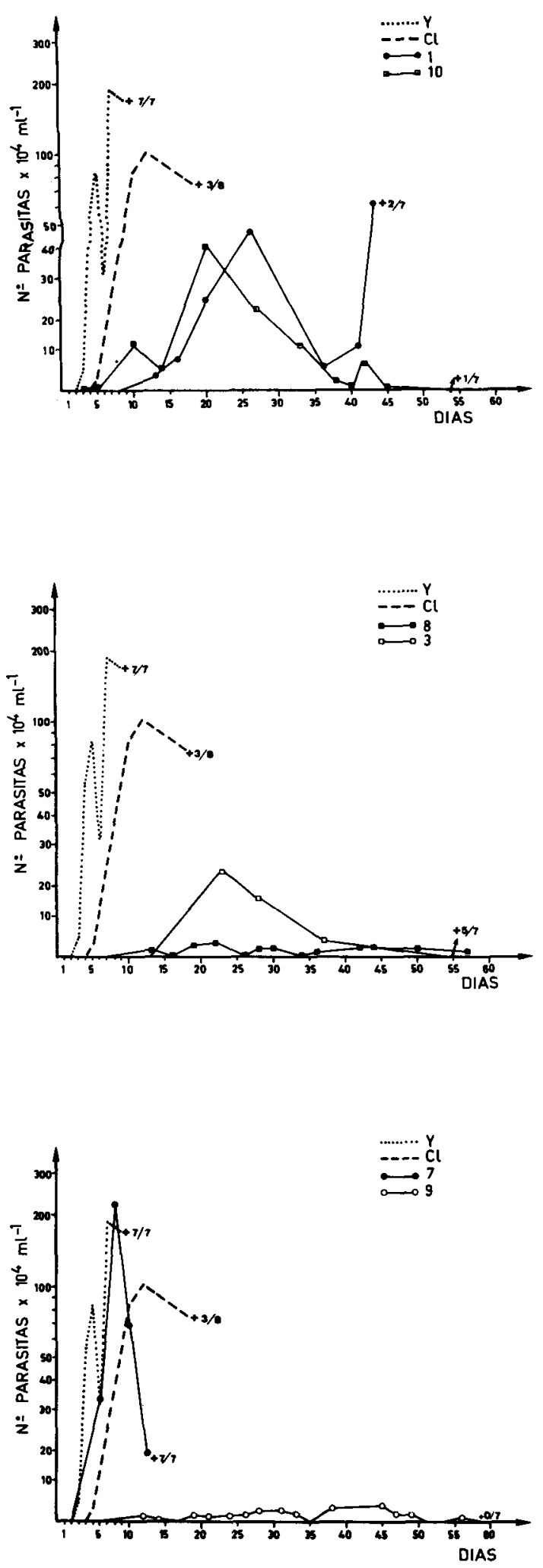
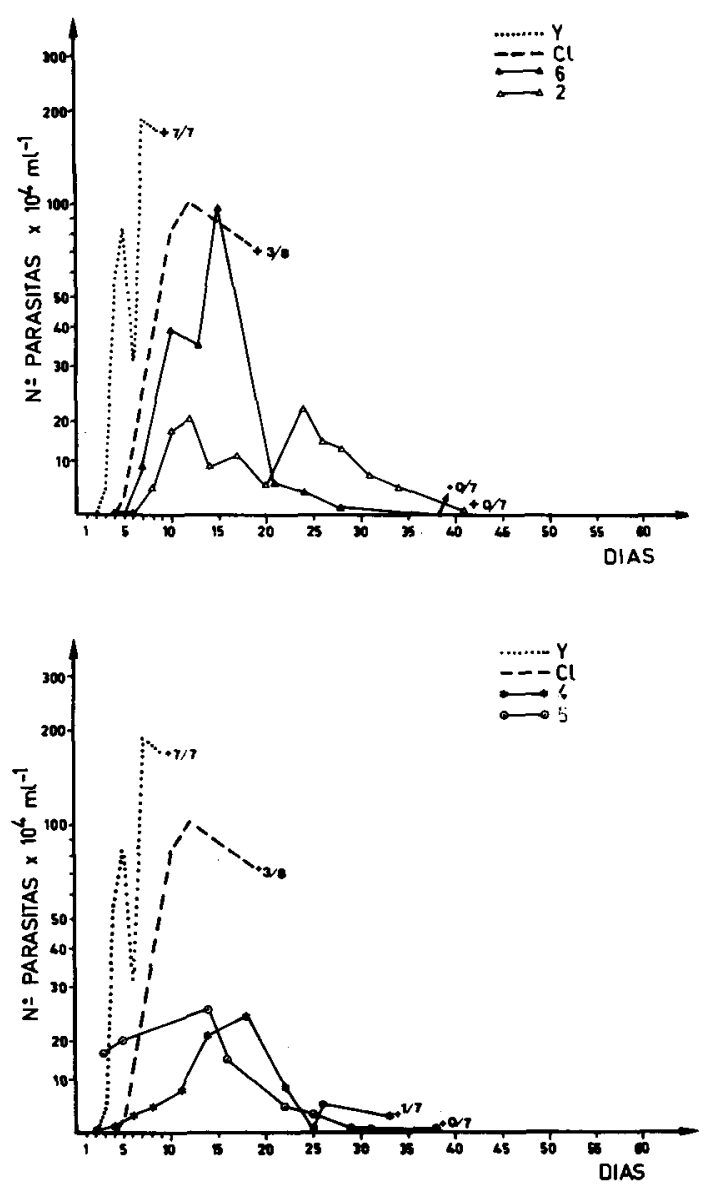

Fig. 1. Curvas de parasitemia em grupos de camundongos inoculados com $10^{5}$ formas tripomastigotas sanguíneos dos estoques de $T$. cruzi $1,2,3,4,5,6,7,8,9$ e 10 comparados com as cepas $Y$ e CL.

Com respeito à intensidade da parasitemia, os estoques $3,4,5,8$ e 9 produziram baixas parasitemias nas fêmeas enquanto os estoques $1,2,6,7$ e 10 produziram parasitemias mais altas. Nos machos, as parasitemias foram, contudo, sempre mais altas do que das fêmeas. Os estoques $3,4,5$ e 7 produziram infecçбes caracterizados por um único pico de parasitemia o qual aparece na 1a (estoque 7), na 2a (estoques 5 e 6 ) ou mesmo mais tarde, isto é, na 3ạ ou 4ạ semanas após a infecção (estoques 3 e 4). Os estoques 1, 2, 8, 9 e 10 induziram infecçס̄es caracterizadas pelo aparecimento de mais de um pico conspícuo de parasitemia. As infecçðes produzidas pelos estoques $2,4,5,6$ e 8 não foram letais, sendo que a grande maioria dos animais evoluiu para a cronicidade. Os demais estoques produziram infecçðes caracterizadas por 
Kipnis TL, Minóprio PM, Luquetti AO, Rassi A, Dias da Silva W. Estudo imunobiológico de estoques de Trypanosoma cruzi isolados de pacientes na fase aguda da doénça de Chagas. Revista da Sociedade Brasileira de Medicina Tropical 16:175-183, Out-Dez, 1983

letalidade variável de acordo com o sexo do camundongo. Neste particular, sobressaem os estoques 3, 6 e 7, os quais produziram mortalidade elevada sendo que o estoque 6 só induz em camundongos machos. A diferença na virulência dos estoques de $T$. cruzi foi analisada com inóculos de $10^{3}$ e $10^{4}$ tripanossomas de dois estoques polares com respeito a este parâmetro, 0 estoque 7 virulento e $o$ estoque 8 avirulento. Verificou-se que o estoque 7 induziu mortalidade mesmo com inóculos menores. Finalmente, como observação adicional, o estoque de virulência mais pronunciada (estoque 7) produziu infecção com padrão similar à produzida pela cepa $Y$. Nenhum dos estoques restantes produziu infecção semelhante à produzida pela cepa $C L$.

Distribuição tecidual dos parasitos e das lesбes - $O$ exame histopatológico de cortes do coração colhidos à época dos picos de parasitemia revelou, consistentemente, a presença de pseudocistos contendo amastigotas nas fibrocélulas cardíacas, principalmente naquelas das paredes ventriculares. Infiltrados constituídos predominantemente por células mononucleares ao lado de uma quantidade variável, porém substancial, de leucócitos polimorfonucleares, constituiu achado freqüente não só próximos a pseudocistos íntegros ou rompidos, mas mesmo em áreas dos cortes de coração aparentemente sem células contendo formas amastigotas de $T$. cruzi Nos cortes de coração obtidos de camundongos na fase crônica da infecção, tanto pseudocistos de amastigotas como lesðes características da miocardite descrita acima foram, de outro lado, consistentemente ausentes.

O exame histopatológico dos demais órgãos, isto é, baço, diafragma, fígado, esôfago, duodeno, jejuno-íleo, colo e ceco, não revelou a presença de pseudocistos de amastigotas, salvo em um caso (estoque 7) no qual foram encontrados raros pseudocistos no baço. $\mathrm{O}$ exame dos tripanossomas corados pelo Giemsa revelou a presença, tanto de formas finas como de formas largas, nas preparações obtidas dos 10 estoques estudados.

Resistência à infecção - Na Tabela 3 estão representados os resultados de tentativa de reinfecção de camundongos sobreviventes à primo-infecções com alguns estoques de $T$. cruzi e, posteriormente, desafiados com inóculos de tripomastigotas sangüíneos das cepas Y e CL. Pelo fato dos camundongos fêmeas serem mais resistentes à infeç̧ão pelo $T$. cruzi, decidiu-se usar somente camundongos deste sexo no experimento. Os resultados mostram que camundongos na fase crônica da infecção produzida pelos tripanossomas do estoque 7 são resistentes à reinfecção por tripanossomas das cepas $\mathrm{Y}$ e CL; enquanto que camundongos na fase crônica da infecção produzida por tripanossomas dos estoques 2,5 e 8 apresentam parasitemia discreta após desafio com tripanossomas de cepa CL. Os camundongos primo-infectados com o estoque 5 não apresentaram parasitemia patente após a infeç̧ão pela cepa $Y$.

Tabela 3 - Resistência induzida pela primo-infecção com alguns estoques de Trypanosoma cruzi isolados de pacientes na fase aguda da doença de Chagas à reinfecção.

\begin{tabular}{|c|c|c|c|c|c|}
\hline \multirow{2}{*}{\multicolumn{2}{|c|}{ Camundongos primo-infectados ${ }^{g}$}} & \multicolumn{4}{|c|}{ Desafio com $10^{5}$ tripanossomas: } \\
\hline & & \multicolumn{2}{|c|}{ Cepa $Y$} & \multicolumn{2}{|c|}{ Cepa CL } \\
\hline Estoque $n ?$ & Inóculo & Parasitemia & Letalidade & Parasitemia & Letalidade \\
\hline 2 & $10^{4}$ & - & - & + & 0 \\
\hline$(7)^{b}$ & $10^{5}$ & + & 0 & + & 0 \\
\hline $\begin{array}{l}5 \\
(7)\end{array}$ & $10^{5}$ & 0 & 0 & + & 0 \\
\hline $\begin{array}{l}7^{c} \\
(6)\end{array}$ & $10^{3}$ & 0 & 0 & 0 & 0 \\
\hline $\begin{array}{l}8 \\
(7)\end{array}$ & $10^{3}$ & + & 0 & + & 0 \\
\hline
\end{tabular}

a - Camundongos não isogênicos primo-infectados e desafiados 4 meses depois com parasitemia negativa.

b - Número de camundongos desafiados com as cepas $Y$ e CL. c - Camundongos primo-infectados com $10^{3}$ formas
sangüíneas. 
Kipnis TL, Minoprio PM, Luquetti AO, Rassi A, Dias da Sïva W. Estudo imunobiologico de estoques de Trypanosoma cruzi isolados de pacientes na fase aguda da doénga de Chagas. Revista da Sociedade Brasileira de Medicina Tropical 16:175-183, Out-Dez, 1983

porém não na fase crônica da infecção. Como 8 destes estoques de tripanossomas foram obtidos de indivíduos provenientes do mesmo município, a variabilidade dos diferentes estoques poderia ser atribuída a um efeito seletivo exercido pelo próprio hospedeiro. Tal suposição, conquanto necessite estudos mais cuidadosos, é reforçada pelo fato de os estoques 2 e 3 haverem sido isolados simultaneamente de duas irmãs, habitantes de uma mesma casa e que contraíram a infecção à mesma época, uma na fase aguda sintomática e a outra, oligossintomática ou alternativamente os parasitos destes estoques poderiam induzir imunossupressão em alguns hospedeiros ${ }^{14}$. Tal variabilidade foi também notada, quando animais na fase crônica da infecção produzida por alguns destes estoques eram desafiados com inóculos letais de tripanossomas das cepas Y ou CL. Observou-se, em alguns casos, (estoques 2, 5 e 8) parasitemias baixas, porém patentes, após o inóculo desafiante. Esta variação poderia ser devido a: I) diferenças na capacidade de modificar os processos de imunoregulação em funcionamento durante a infecção ou II) a presença nos tripanossomas de alguns epítopos diferentes. De outro lado, a existência de epitopos comuns é evidente face os resultados de imunoproteção cruzada. Experimentos recentes mostraram que camundongos infectados com tripanossomas da cepa $Y$ produzem anticorpos predominantemente confinados aos isotipos IgG2a e IgG2b, porém ausentes ou em niveis muito baixos no isotipo $\operatorname{IgG1} 1^{17}$. O fracionamento dos soros dos camundongos infectados com alguns destes estoques em coluna de proteína A-Sepharose, revelou que as quantidades de IgG eluidas com tampões de $\mathrm{pH}$ 6,5, pH 5,5 e pH 2,5 e cujos eluatos contém respectiva e predominantemente $\operatorname{IgG} 1, \operatorname{IgG} 2 \mathrm{~b}$ e $\operatorname{IgG} 2 b+\operatorname{IgG} 2 a$, variam consideravelmente segundo a origem dos tripanossomas inoculados. Assim, contrariamente ao que ocorre com a cepa $\mathrm{Y}$ a qual induz restrição seletiva de IgG1 específica, a cepa $\mathrm{CL}$ e o estoque 4 produzem um aumento na produção deste isotipo de IgG. Com respeito ao isotipo IgG2a, entre os 5 tripanossomas estudados, (cepa $\mathrm{CL}$ e estoques 4, 7, 8 e 10) somente o estoque 10 não induziu restrição de síntese. Finalmente, com relação ao isotipo IgG2b, observou-se restrição de síntese deste isotipo pelos estoques 7 e 8 e uma significativa potenciação pelo estoque 4 . Estes resultados, conquanto preliminares, sugerem que a restrição seletiva de isotipos de IgG no curso da infecção pelo $T$. cruzi, provavelmente controlada pelo repertório antigênico do parasito se constitua em um dos mecanismos determinantes do direcionamento da infecção ou para o equilíbrio (fase crônica) ou para o desequilibrio (morte do hospedeiro). Tal hipótese não é improvável, uma vez que dois mecanismos efetores admitidos serem importantes no controle da infecção, isto é, lise induzida por anticorpo e complemento ${ }^{10}$ e a citotoxicidade medida por anticorpos e por células 11215 envolvem a participação de IgG $2 b$. Com o propósito de esclarecer o papel dessa regulação - disregulação na produção dos vários isotipos de IgG no destino da infecção, a síntese específica e inespecífica destas imunoglobulinas ao longo da infecção por tripanossomas de diferentes estoques, está sendo investigada neste laboratório. - Os dados da Tabela 1 mostram que nos 10 pacientes dos quais foram isolados os estoques de $T$. cruzi utilizados neste trabalho, a doença apresentou-se com características variáveis. Assim, sinal de Romaña ou Chagoma acompanhados de febre presentes em alguns pacientes eram ausentes em outros. Hipertrofia de linfonodos, hepatomegalia e esplenomegalia conquanto observadas na maioria dos pacientes não foram detectados em alguns. Constantes entretanto, foram a presença de parasitos e de anticorpos específicos no sangue circulantes, este último fato indicando reatividade imunológica. Com respeito a estes dados os pacientes MLSG, SLJ e DPS fornecedores dos estoques de $T$. cruzi de nQ 3, 4 e 6 , respectivamente, apresentaram títulos muito elevados de anticorpos IgM, os dois últimos acompanhados também por altos títulos de IgG detectados por imunofluorescência indiretá. Estas diferenças observadas na evolução da doença adquirida "in natura" reproduziram-se também, embora com outros parâmetros de avaliação, nas infecções experimentais produzidas em camundongos por estes estoques de $T$. cruzi. Tomando-se o parâmetro parasitemia, apenas os estoques 2 e 3 mostraram perfis parasitêmicos semelhantes, os quais, por coincidência, são provenientes dos pacientes MRSG e MLSG duas irmãs que habitavam uma mesma casa. Pelo parâmetro virulência, algun's estoques como por exemplo os de no 7 produziram índices elevados de mortalidade enquanto os demais são de baixa virulência ou mesmo são incapazes de produzir doença de evolução fatal. Com respeito à produção dos diferentes isotipos de IgG nos estoques estudados foram observadas variaçбes marcantes como por exemplo, a produção de IgG2a pelo estoque 10 e de IgG $2 b$ pelo estoque 4 , enquanto que grandes quantidades de IgG1 foram produzidas pela cepa CL e estoque 4. É óbvio que isto se deve à diferenças acentuadas na capacidade dos tripanossomas dos diferentes estoques em estimular o sistema imunitário. Isto se reflete pelo menos em certo grau na 
intensidade da resistência à reinfecções adquiridas pelos animais na fase crônica da infeç̧ão. Muito embora todos os estoques tenham a capacidade de induzir imunidade cruzada a inóculos-desafios com tripanossomas virulentos das cepas Y ou CL esta resistência em certos casos, era menos pronunciada. Isto se deve, provavelmente, à presença de repertórios antigênicos comuns e diferentes na superfície dos tripanossomas estudados. Tais diferenças poderiam responder pelo menos em parte pelas variaçōes nos padrões das infecçōes por eles induzidas.

Este fato já tem sido assinalado por vários autores $^{3}{ }^{4} \mathrm{em}$ cepas de $T$. cruzi isoladas no Recôncavo Baiano, e de pacientes crônicos ${ }^{16}$. No presente trabalho os autores encontraram resultados similares em pacientes na fase aguda. Seria recomendável no futuro o estudo do comportamento de tripanossomas isolados de pacientes na fase aguda assintomática, por ser esta a forma mais freqüente ${ }^{13}$. Uma das razóes pelas quais os pesquisadores preferem a utilização de cepas altamente virulentas é a facilidade de obtenção de um grande número de parasitos, porém, desde que acreditamos ter demonstrado junto com outros autores, que na doença humana este não é o padrão dominante de infecção justifica-se assim o estudo dos estoques menos virulentos com o objetivo de obter resultados comparáveis aos da doença humana. Ressalte-se que neste caso a mortalidade via de regra é inferior a $10 \%$ como aconteceu na maioria dos camundongos inoculados com os diferentes estoques utilizados no presente estudo.

Em conclusão, os nossos resultados permitem assinalar a importância do estudo de outras cepas, convenientemente caracterizadas, em futuros estudos experimentais. $\mathrm{O}$ fato de ter-se achado apenas um estoque com as características de virulência assinaladas para as cepas comumente empregadas nas infecções experimentais, $C L$, Tulahuén e outras permite pressupor-se que na infecção natural em humanos, prevalecem populaçס̄es de tripanossomas com características bem menos virulentas que as descritas na literatura.

\section{SUMMARY}

Ten stocks of trypanosomes isolated from patients at the acute phase of Chagas'disease were injected into groups of outbred normal mice at the doses of $10^{3}, 10^{4}$ and $10^{5}$ parasites/mouse and the course of the infections followed up for 3 months. The parasitemia was usually low, with recurrent peaks, the animals evolving to chronicity, only one of them inducing high ratio of mortality. Patterns of parasitemia and mortality were essentially different for each stock studied; only one stock did show similar patterns to well known strains (Yand CL) commonly used in experimental work.

Parasites and lesions, although detected at the peak of parasitemia and restricted to heart were absent after three months. At this period the Igs profiles showed striking differences with respect to their distribution. Groups of mice that had been inoculated with one of the stocks were challenged with the Y or CL strains.

In some instances low parasitemias although patent were seen after the infecting dose.

Key words: Trypanosoma cruzi. Chagas' Disease. Stocks. Strains. IgG isotypes.

\section{AGRADECIMENTOS}

Os autores agradecem ao Dr. José Florisval de Ornelas pelo encaminhamento dos pacientes da região de Montalvânia e ao Prof. Dr. Ivan Mota, ICB, USP e Centro de Imunologia da OMS pela realização dos testes de dupla-imunodifusão para deteç̧̃̃o dos isotípos de IgG de camundongos. Agradecem também ao Dr. Benedito A. Peres do Instituto de Medicina Tropical de São Paulo pela realização dos testes de Imunofluorescência e Hemaglutinação passiva.

\section{REFERÊNCIAS BIBLIOGRÁFICAS}

1. Abrahamsohn IA, Dias da Silva W. Antibody dependent cell mediated cytotoxicity against Trypanosoma cruzi. Parasitology 75:317-323, 1977.

2. Alcantara $A, B$ Bener $Z$. The in vitro interaction of Trypanosoma cruzi bloodstream forms and mouse peritoneal macrophages. Acta Tropica 35:209-219, 1978.

3. Andrade SG. Caracterização de cepas do Trypanosoma cruzi isolados no Recôncavo Baiano. (Contribuição ao estudo da patologia geral da doença de chagas em nosso meio). Revista de Patologia Tropical 3:65$-121,1974$. 
4. Andrade SG. Tentative for grouping different Trypanosome strains in some types. Revista do Instituto de Medicina Tropical. São Paulo 18: 140-141, 1976.

5. Brener Z. Contribuição ao estudo da terapêutica experimental da doença de chagas. Tese Universidade de Minas Gerais, Brasil, 1961.

6. Camargo ME. Fluorescent antibody test for the diagnosis of American trypanosomasis. Technical modification employing preserved cultured forms of Trypanosoma cruzi in a slide test. Revista do Instituto de Medicina Tropical de São Paulo 8:227-234, 1966.

7. Freitas JLP, Almeida JO. Nova técnica de fixação do complemento para moléstia de Chagas. Reação quantitativa com antígeno gelificado de culturas de Try. panosoma cruzi. Hospital 35:787-800, 1949.

8. Hauschka TS. Sex of host as a factor in Chagas' disease. Journal of Parasitology 33: 399-404, 1947.

9. Kipnis TL, Calich VLG, Dias.da Silva W. Active entry of bloodstream forms of Trypanosoma cruzi in to macrophages. Parasitology 78:89-98, 1979.

10. Krettli AU, Brener Z. Protective effects of specific antibodies in Trypanosoma cruzi infections. The Journal of Immunology 116: 755-760, 1976.

11. Lowry $\mathrm{OH}$, Rosenbrough NJ, Far $\mathrm{AL}$ and Randall RJ. Protein measurement with the folin phenol rea- gent. The Journal of Biochemistry 193: 265-275, 1951.

12. Okabe K, Kipnis TL, Calich VLG, Dias da Silva W. Cell mediated cytotoxicity to Trypanosoma cruzi: Antibody dependent cell mediated cytoxicity to Trypomastigote bloodstream forms. Clinical Immunology and Immunopathology 16: 344-353, 1980.

13. Rassi A. Clínica: Fase Aguda. In Brener $Z$ e Andrade $Z$ (ed) Trypanosoma cruzi e Doença de Chagas, $1^{\text {a }}$ edição. Guanabara Koogan S.A. Rio de Janeiro p. $249-264,1979$.

14. Reed SG, Larson CL, Speer CA. Supression of cell mediated immunity in experimental Chagas' disease. Zeitscrift Parasitenkund 55: 11,17, 1977.

15. Sanchez GA, Krettli AU, Brener Z. In: Resumos da IX Reunião Anual de Pesquisa Básica em Doença de Chagas, Caxambú, Brasil p. 77, 1982.

16. Schlemper $B R$, Ávila $B M$, Coura $J R$ e Brener $Z$. Course of infection and histopathological lesions in mice infected with seventeen Trypanosoma strains isolated from chronic patients. Revista da Sociedade Brasileira de Medicina Tropical 16:23-30, 1983.

17. Scott MT, Moyes L. Specific IgG isotype restriction in mice infected with Trypanosoma cruzi. In: Abstracts of the International Congress of Parasitology, Canadá, p. 49, 1982. 